\title{
DIRECT EFFECT OF BILE ON COLONIC MUCOSA IN ALIMENTARY INDUCED HYPERLIPIDEMY IN RATS
}

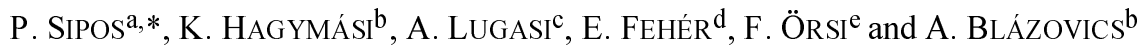 \\ ${ }^{a}$ II. Department of Surgery, Semmelweis University, H-1125 Budapest, Kútvölgyi u. 4. Hungary \\ ${ }^{b}$ II. Department of Medicine, Semmelweis University, Budapest. Hungary \\ ${ }^{\mathrm{c}}$ Fodor József National Centre of Public Health, \\ National Institute of Food Hygiene and Nutrition, Budapest. Hungary \\ ${ }^{\mathrm{d}}$ Department of Anatomy, Semmelweis University, Budapest. Hungary \\ ${ }^{\mathrm{e}}$ Technical University of Budapest, Budapest. Hungary
}

(Received: 7 February 2000; accepted: 18 September 2000)

An experimental surgical model was developed in rats after a short term alimentary induced hyperlipidemy to study the direct effect of bile on the colonic mucosa, with regard to the cancerogenic properties of lipid rich diet. The purpose of this study was to light on the role of fatty acid alteration and lipid peroxidation processes of bile in the epithelial cell damage. Animals were fed with normal (group A) and fat rich diet (group B) for 10 days and then bile samples were collected by the cannulation of the common bile duct in deep anaesthesia. The circulation preserved colons of control rats were treated either with bile from the control or hyperlipidemic rats. The treatment was carried out for 30 minutes.

The electronmicroscopic alterations of epithelial cells (both enterocytes and goblet cells) caused by bile from hyperlipidemic rats were significantly greater than that of controls.

Unfavourable changes of the redox state of the colonic mucosa were also detected both in the hyperlipidemic and bile treated groups. A significant increase was observed in the free-SH concentration of the two bile treated groups against the untreated animals. The changes could be explained among others by the modified bile fatty acid composition. The present study supports that the alimentary modified bile can influence the structure of the epithelium of colonic mucosa and it can be one of the inducing factor of carcinogenesis.

Keywords: hyperlipidemy, colonic mucosa, bile, electronmicroscopy, redox state

Colon cancer is the most common gastrointestinal neoplastic disease in the Western world. It is generally agreed that the composition of diet plays a fundamental role in the induction of this type of cancer (POTTER et al., 1993). Diet high in animal fat and low in fiber has a high incidence of colorectal cancer. High fiber diet may decrease

* To whom correspondence should be addressed.

E-mail: speter@kut.sote.hu; Fax: (36-1) 3754291 
the colonic transit time and thus can increase the bulk of stool, may dilute the carcinogens and decrease the contact time of the carcinogens. Diet can affect colonic carcinogenesis by increasing cell proliferation and it can alter the genotoxic effect of carcinogens or it can modify the growth and progression of cells initiated by carcinogens. Persons on high fat diet excrete three times as much bile acids compared to vegetarians and their intestinal flora is changed, which alters the transformation of primary bile acids. From the primary bile acids excreted by hepatocytes secondary bile acids are formed in the intestine by bacterial modification of the nuclear hydroxyl group (SEYMOUR et al., 1989).

The secondary bile acids are believed to be the promoters of colorectal cancer (BAIJAL et al., 1998a, PEIFFER et al., 1997). The change in the composition of bile acids can induce damage to the mucosa, the innermost layer of the colon (MARTINEZ et al., 1998) and can influence the proliferation rate of colonic mucosa cells.

Lipid peroxidation products were detected both in human bile after cholecystectomy, and in chicken gallbladder bile as well as in model bile, verifying the importance of free radicals in gallstone diseases (ABDEL RAHMAN et al., 1995; BLÁzOviCS et al., 1996; EDER et al., 1996; SIPOS et al., 1997) and these products can alter the composition of bile, thus inducing further reactions in the intestine.

Bile is normally present in the colon and it may modulate the structure of the epithelium, the innermost cell layer of the colonic mucosa. It is not known yet how these effects occur in vivo. Therefore the purpose of this study was to examine the direct effects of bile on colonic mucosa using histological and biochemical investigations.

\section{Materials and methods}

\subsection{Animal feeding study}

All experimental procedures used conformed to the "Revised Guide for the Care and Use of Laboratory Animals" (1996), as well as specific national laws (1998). (Permission Number: TUKEB 59/1996 Semmelweis University).

Twenty male adult Wistar albino rats weighing 150-200 g were used after short term diet. The animals were randomly divided into 2 groups: group A: 10 animals were fed with normal chow (Charles River Hungary Kft.), being the control. Group B: 10 animals had lipogenic diet consisted of $2 \%$ cholesterol, $20 \%$ sunflower oil and $0.5 \%$ cholic acid added to the normal chow. All of the animals had water ad libitum during the whole period (BLÁzOVICS et al., 1996).

After 10 day feeding period they were anaesthetised with Nembuthal $50 \mathrm{mg} / \mathrm{b}$.w.kg dose, for deep narcosis. Then the common bile duct was cannulated and approximately 3-4 ml bile/rat was collected from both group (A, B). 
In two other groups (5-5 rats fed with normal chow) the ascending colon was banded in order to protect the ileal backflow and $0.5 \mathrm{ml}$ pooled bile sample from the controls (group C) and from the hyperlipidemic rats (group D) was injected in the ascending and descending circulation preserved colon. After 30 min incubation with bile samples, the colon was removed and gut lumen was washed with isotonic $\mathrm{KCl}$ solution. Small pieces of the colon were cut and put in fixative solutions for electronmicroscopy.

Small pieces of the colon were fixed in $4 \%$ neutral buffered formalin, embedded in paraffin and $5 \mu \mathrm{m}$ thin slices were cut and stained with haematoxilin-eosin.

\subsection{Electronmicroscopy}

For electronmicroscopical investigations the materials were fixed with a fixative solution containing $4 \%$ paraformaldehyde and $1 \%$ glutaraldehyde in phosphate buffer ( $\mathrm{pH}$ 7.2). The samples were postfixed in $1 \%$ osmium tetroxide and embedded in Epon. Ultrathin sections were stained with uranyl acetate and lead citrate, then examined with Jeol 100 electromicroscope.

\subsection{Biochemical measurements}

The reducing power property was determined by the spectrophotometric method of OYAIZU (1986) at $700 \mathrm{~nm}$. Free SH-group concentrations were determined by the SEDLAK and LINDSAY (1968) method based on ELLMANN (1959) reaction, with the detection of 2-nitro-5-mercapto-benzoic acid at $440 \mathrm{~nm}$. The proton donating ability was measured in the presence of 1,1-diphenyl-2-picrylhydrazyl (DPPH) radical (BLOIS, 1958 and HATANO et al., 1988). Hyperlipidemy was checked by serum parameters (alkaline phosphatase, aspartate and alanine aminotransferases, $\gamma$-glutamyl transferase, total cholesterol, triglycerides) (BLÁzOVICS et al., 1996). Protein contents of homogenates of colonic mucosa were measured by the method of LOWRY and coworkers (1951).

Fatty acid analysis of bile juice was carried out by gaschromatographic techniques. Lipid fraction was isolated with chloroform:methanol 2:1 mixture. Chloroform phase $\left(1 \mathrm{~cm}^{3}\right)$ was analysed after dehydration and esterification. The lipids were saponified by $5 \%$ sodium hydroxide in $50 \%$ aqueous methanol and the fatty acids were esterised by $10 \%$ boron trifluorid methanol reagent. The fatty acids were extracted by hexane and purified by silica gel column chromatography according to ALEXANDER and co-workers (1985). 


\subsection{Gas chromatography}

Hewlett-Packard 5890 gas chromatography with flame ionisation detector and split capillary injector was used for the analysis. Column: Carbowax 20M ( $25 \mathrm{~m} \times 0.2 \mathrm{~mm}$, ID. $0.25 \mu \mathrm{m}$ film thickness), injector: split, split ratio:1:50, temperature column oven $180^{\circ} \mathrm{C}$, injector $280{ }^{\circ} \mathrm{C}$, detector $205^{\circ} \mathrm{C}$, carrier gas: nitrogen $0.3 \mathrm{~cm}^{3} \mathrm{~min}^{-1}$, detector gas: hydrogen $30 \mathrm{~cm}^{3} \mathrm{~min}^{-1}$, air $400 \mathrm{~cm}^{3} \mathrm{~min}^{-1}$. The peaks were identified by comparison with behaviour of known standards of SUPELCO FAME mixtures (SIGMA, St. Luis).

Stable radical 1,1-diphenyl-2-picrylhydrasyl (DPPH) was obtained form SIGMA (St. Luis), serum bovine albumin from CALBIOCHEM AG (Lucerne). All other reagents were purchased from REANAL (Budapest).

\subsection{Statistical analysis}

All values are presented as mean \pm standard error of the arithmetic mean. The differences between the 2 groups were examined by Student's $t$ probe. Differences were considered statistically significant at $\mathrm{P}<0.05$.

\section{Results}

The epithelial lining of the colon was disrupted (Fig. 1), the quantity of the goblet cells significantly decreased and a large number of inflammatory cells appeared in the tunica mucosa of the colon treated with bile from animals fed with fat rich diet (group D) comparing to the control and rats fed with fat rich diet (group A, B). Electronmicroscopic investigations showed that the epithelial lining of the colonic mucosa changed, the mucopolysaccharide surface coat disappeared in the animals fed with fat rich diet and treated with bile (group B, C, D). Figure 2 shows the enterocytes with a large number of microvilli from the control colonic mucosa. The microvilli of the epithelial cells (both the enterocyte and goblet cells) were reduced in hyperlipidemic rats. A slight inflammatory reaction was also observed in the tunica propria. After bile treatment the cell membranes of them were disrupted, bile was observed in the cytoplasma establishing lysosomes (Fig. 3). The changes of the epithelial lining were more evident in the animals treated with bile from the fat rich diet group (D) (Fig. 4). The number of the goblet cells $/ 100 \mu \mathrm{m}$ was decreased (group B, C, D) significantly compared to the group A. The epithelial cells disappeared showing ulcer like abnormality in some parts of the colonic mucosa of the D group. 


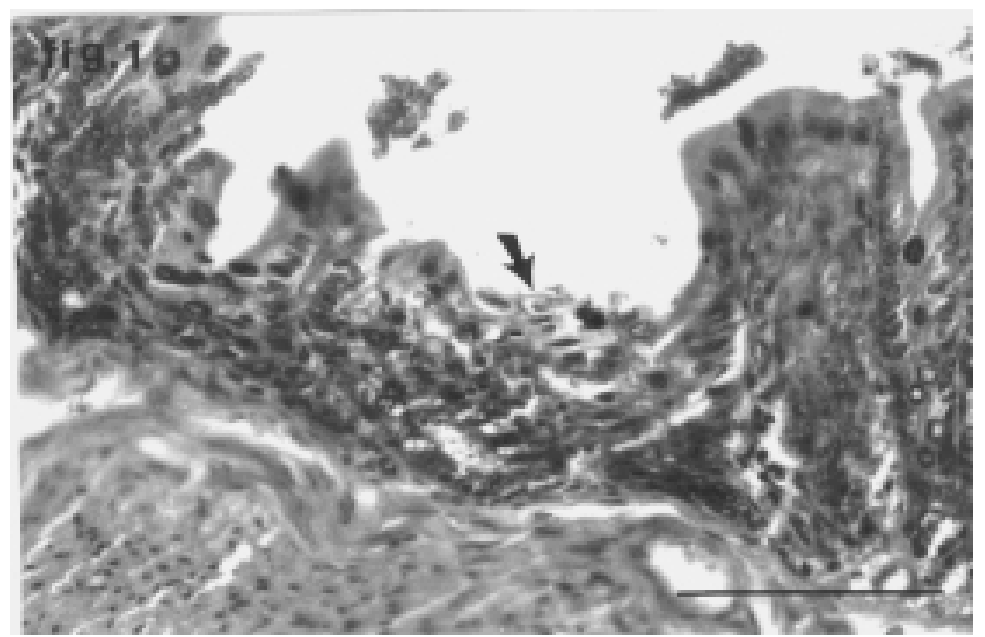

Fig. 1. Part of the tunica mucosa of bile treated rat after fat rich diet. Arrow points disruption of the epithelium infiltrated with inflammatory cells. Bar scale $=100 \mu \mathrm{m}$

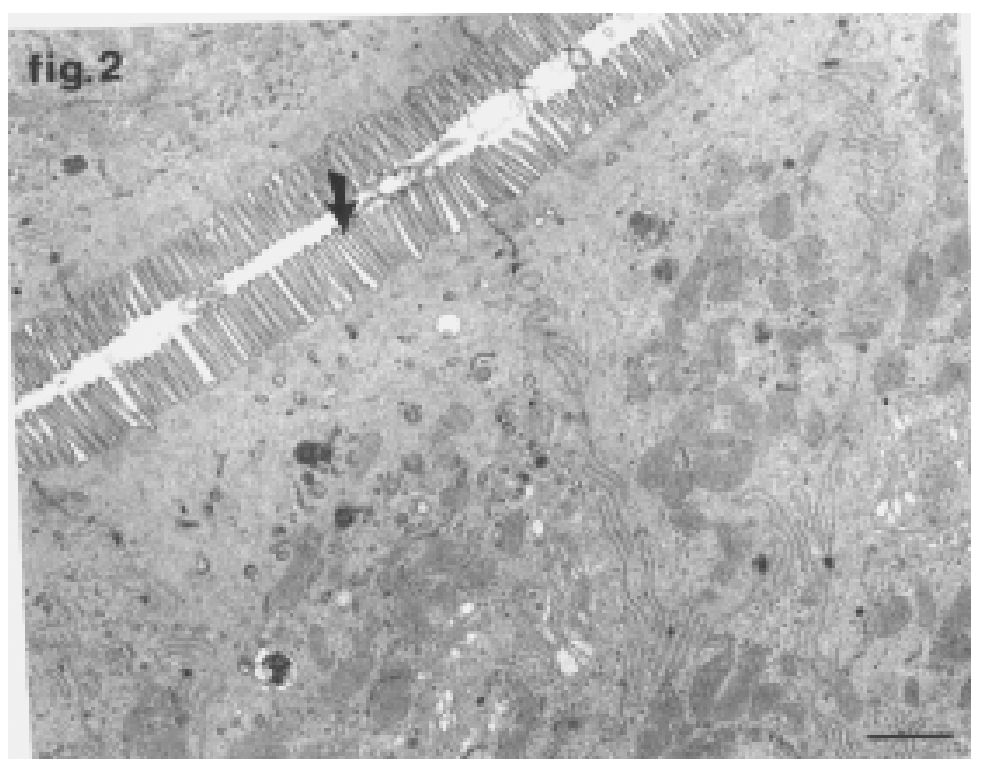

Fig. 2. A part of the enterocyte with a large number of microvilli (arrow) from the normolipidemic rat 


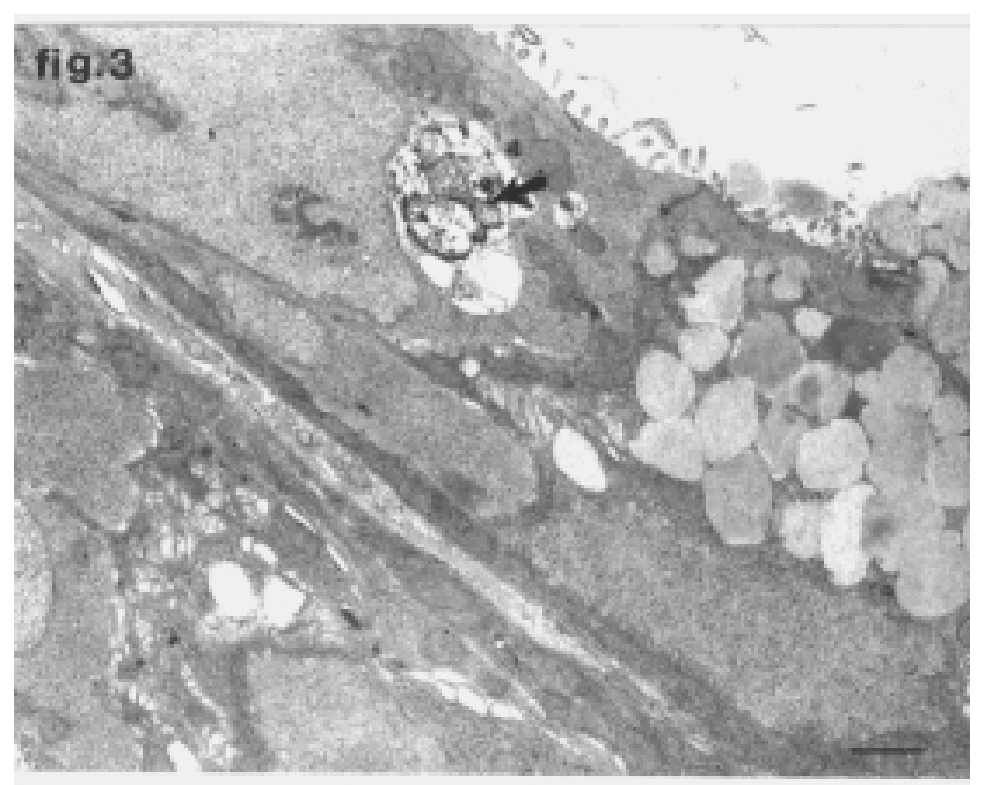

Fig. 3. A part of the colonic mucosa from the animal treated by bile (group C). Arrow points the lysosome having bile in it. Bar scale $=1 \mu \mathrm{m}$

After fat rich diet the free-SH concentration of the colonic mucosa decreased significantly (group B) compared to control. The free-SH group concentration was elevated in group $\mathrm{C}$ and $\mathrm{D}$ in comparison with group $\mathrm{A}$, which may be in connection with liberation of membrane bound proteins and/or enzymes from membrane structure as a consequence of bile treatment (Fig. 5).

A fall was observed after fat rich diet (B) in the proton donor activity and significant difference was measured between the bile treated groups (C-D) (Fig. 6). The reducing activity was significantly lowered in group $\mathrm{B}$, and in both bile treated groups (C-D). There was no statistically significant difference among these groups (Fig. 7). Membrane destruction and inflammatory reaction (see the electronmicroscopic pictures) were supposed as the reasons for the changes in these parameters. 


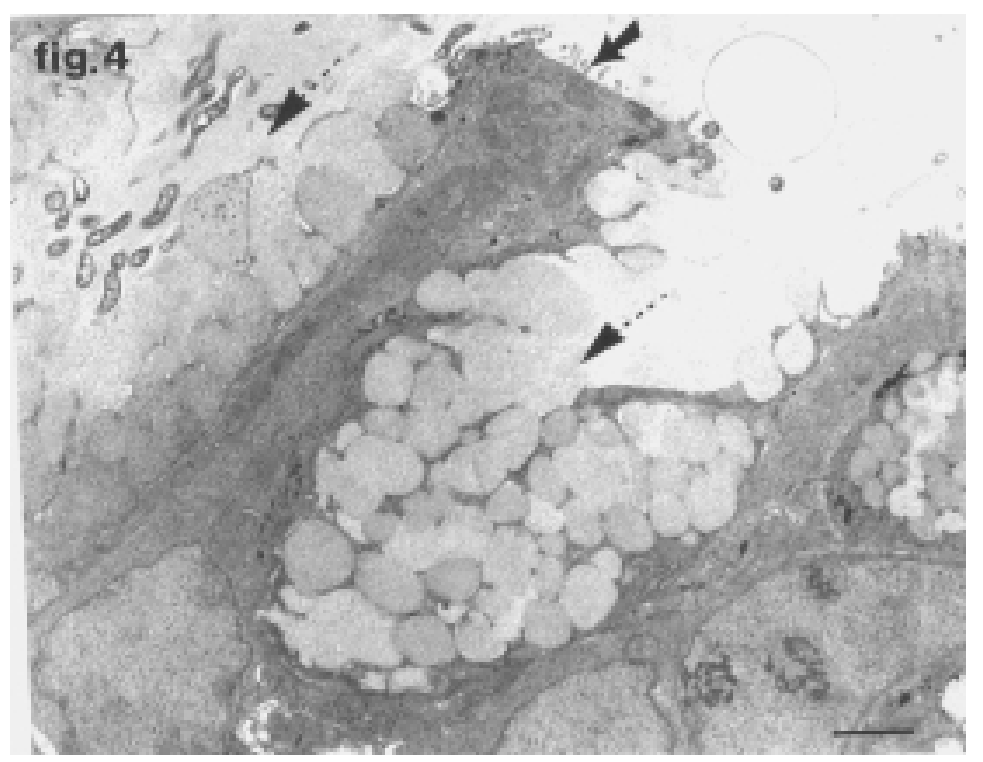

Fig. 4. A part of the colonic mucosa after bile treatment from the hyperlipidemic rat (group D). Arrows point the reduced microvilli of the enterocytes. Dotted arrows show the disrupted goblet cells. Bar scale $=1 \mu \mathrm{m}$

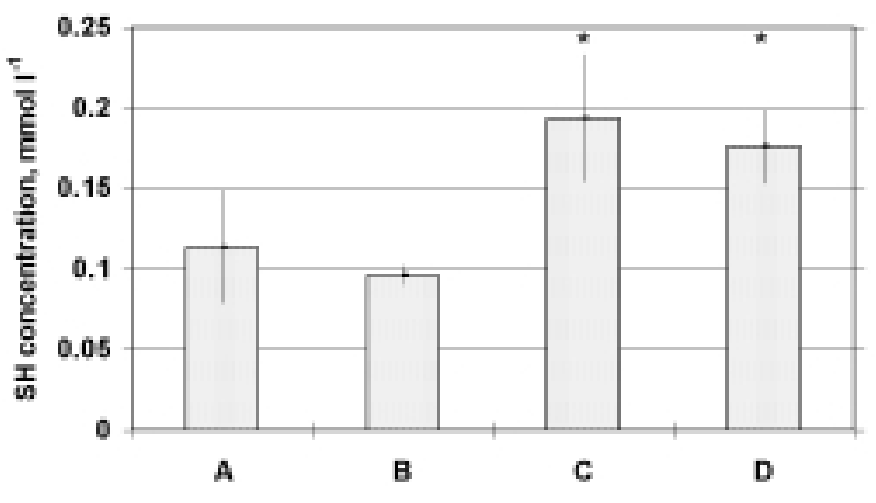

Fig. 5. Free $\mathrm{SH}$ group concentration $\left(\mathrm{mmol}^{-1}\right)$ in group A, B, C, D. * shows the significant difference between A-C, A-D. Group A: control colonic mucosa, group B: colonic mucosa of rats fed with fat rich diet, group $\mathrm{C}$ : control bile treated colonic mucosa, group D: colonic mucosa of rats after bile treatment (from hyperlipidemic animals) 


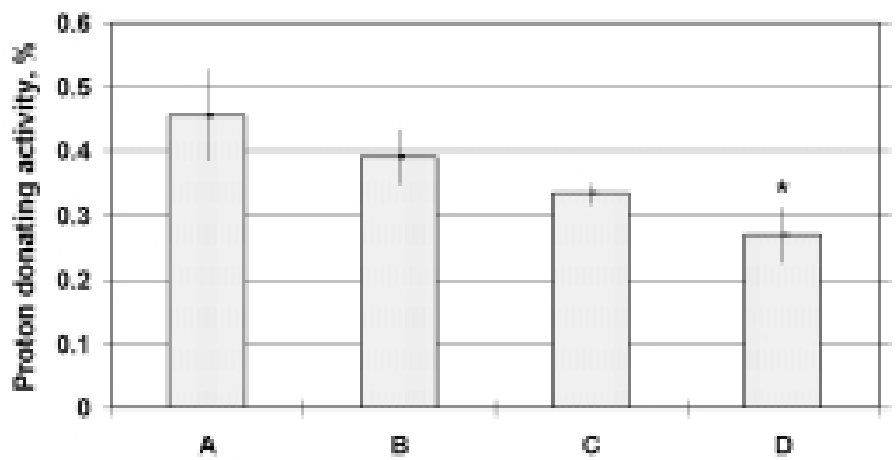

Fig. 6. The proton donating ability (\%) in group A, B, C, D. * shows the significant difference between C-D. Group A: control colonic mucosa; group B: colonic mucosa of rats fed with fat rich diet; group C: control bile treated colonic mucosa; group D: colonic mucosa of rats after bile treatment (from hyperlipidemic animals)

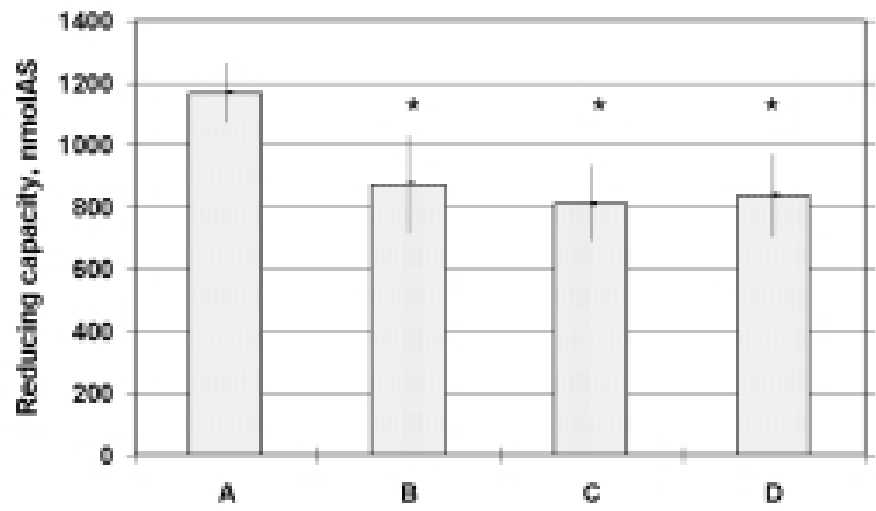

Fig. 7. The reducing power (nmolAS) comparing to group A, B, C, D. * shows the significant difference between A-B, A-C, A-D. Group A: control colonic mucosa; group B: colonic mucosa of rats fed with fat rich diet; group C: control bile treated colonic mucosa; group D: colonic mucosa of rats after bile treatment (from hyperlipidemic animals) 
Table 1

Fatty acid composition of bile in control and in hyperlipidemic rats

\begin{tabular}{lrr}
\hline Fatty acids & $\begin{array}{c}\text { Normolipidemy } \\
(\% \pm S D)\end{array}$ & $\begin{array}{c}\text { Hyperlipidemy } \\
(\% \pm S D)\end{array}$ \\
\hline $\mathrm{C} 12: 0$ & $1.45 \pm 0.55$ & $0.26 \pm 0.04$ \\
$\mathrm{C} 14: 0$ & $2.14 \pm 0.29$ & $3.34 \pm 2.91$ \\
$\mathrm{C} 15: 0$ & $0.88 \pm 0.75$ & $1.47 \pm 0.65$ \\
$\mathrm{C} 16: 0$ & $21.09 \pm 2.06$ & $19.58 \pm 0.44$ \\
$\mathrm{C} 16: 1$ & $0.70 \pm 0.63$ & $4.02 \pm 3.35$ \\
$\mathrm{C} 18: 0$ & $21.53 \pm 4.17$ & $8.10 \pm 3.48$ \\
$\mathrm{C} 18: 1$ & $34.96 \pm 3.26$ & $23.29 \pm 8.71$ \\
$\mathrm{C} 18: 2$ & $10.52 \pm 2.36$ & $17.54 \pm 3.33$ \\
$\mathrm{C} 18: 3, \mathrm{C} 19: 0$ & $1.99 \pm 0.34$ & $1.87 \pm 0.69$ \\
$\mathrm{C} 20: 0$ & $0.54 \pm 0.18$ & $6.22 \pm 0.68$ \\
$\mathrm{C} 20: 2$ & $1.70 \pm 0.87$ & $3.01 \pm 0.17$ \\
$\mathrm{C} 20: 3$ & $0.63 \pm 0.00$ & $2.04 \pm 0.85$ \\
\hline
\end{tabular}

The fatty acid composition of bile of hyperlipidemic rats was also changed and the rate of polyunsaturated fatty acid components were significantly higher in it. Consequently this modified bile served as a lipid peroxidation precursor and immune stimulants (Table 1).

\section{Conclusions}

In a healthy person only small amount of fat reaches the large bowel. The amount of free fatty acids, especially long-chain and saturated fatty acids reaching the colon is elevated in fat malabsorption for example due to pancreatic insufficiency, cholestatic liver disease, mucosal abnormalities. Colonic bacteria can metabolize dietary fatty acids to produce hydroxy-fatty acids, which are potentially toxic, but long-chain polyunsaturated fatty acids have a powerful antibacterial effect in the colon. Change in the composition of bile influences the metabolism of colonocytes as well (LING \& WEAVER, 1997). After cholesterol feeding bile acid pool and cholic acid synthesis were increased (XU et al., 1998).

In this present study the alterations (e.g. reduction of microvilli and goblet cells, disruption of the cell membranes) of the epithelial lining caused by bile from hyperlipidemic rats were proved by electronmicroscopy as well as by biochemical investigations. Significant changes were measured in the redox state of normal colonic mucosa as a consequence of hyperlipidemic and control bile administration. These 
effects may be in concordance with the changes in the composition of bile fatty acids and/or bile acids. The higher rate of polyunsaturated fatty acids could influence the prostaglandin biosynthesis and stimulate the immune responses, which can be seen in the electronmicroscopic picture (Fig. 3).

Changes in the composition of bile acids can alter the colonic mucin production and intestinal cytoprotection (SHEKELS et al., 1996). Bile acids in the colon can increase the release of prostaglandin E2 and nitrates plus nitrites via NO-synthese (CASELLAS et al., 1996). Secondary bile acid deoxycholate in pharmacological concentration induces hyperproliferation in vitro (VELAZQUEZ et al., 1997). In tumor cell lines chenodeoxycholic or deoxycholic acid caused morphological changes, that were characteristic of apoptosis, whereas incubating cells with ursodeoxycholic acid inhibited cell proliferation but did not induce apoptosis (MARTINEZ et al., 1998). Another possibility for the injury role of bile acids, that primary and secondary bile acids can inhibit xenobiotic metabolising enzymes such as glutathion S-transferase and UDP-glucuronyl-transferase (BAIJAL et al., 1998b). In rat model dietary restriction increased bile flow compared to age matched ad libitum fed rats, and it was associated with higher biliary GSH secretion rate and resulting in enhance GSH and GSH derived thiols supply to the intestinal lumen (BOUCHARD et al., 1998).

The present study supports that the hyperlipidemic diet can modify the structure of epithelium of the colonic mucosa (FEHÉR et al., 1993) as well as the composition of bile acid pool significantly. The cell proliferation inducing property of the hiperlipidemic diet can take part in adenoma formation and carcinogenesis.

We would like to express our thanks to Mrs. S. BÁRKOVICS and Mrs. E. PINTÉR for their excellent technical assistance.

The research was supported by the National Scientific Research Foundation (OTKA F 029252) and Ministry of Welfare ETT 02-517.

\section{References}

ABDEl-RAHMAN, M., BlÁZOVICS, A., ÁGOStON, M., ASZTAlos, I., Prechl, J., VAllent, K. \& FEHÉR, J. (1995): A chemiluminescent study for detection of free radicals in gallbladder bile in gallstone diseases. Ces. A Slov. Gastroent., 45 (1), 7-13.

ALEXANDER, L. R. \& JUSTICE, J. B. (1985): Fatty acid composition of human erythrocyte membranes by capillary gas chromatography-mass spectrometry. J. Chromatogr., 342, 1-12.

BAIJAL, P. K., FITZPATRICK, D. W. \& BIRD, R. P. (1998a): Comparative effects of secondary bile acids, deoxycholic and lithocholic acids, on aberrant crypt foci growth in the postiniation phases of colon carcinogenesis. Nutr. Canc., 31(2), 81-9. 
BAIJAL, P. K., FITZPATRICK, D. W. \& BIRD, R. P. (1998b): Modulation of colonic xenobiotic metabolizing enzymes by feeding bile acids: comparative effects of cholic, deoxycholic, lithocholic and ursodeoxycholic acids. Fd \& Chem. Toxicol., 36(7), 601-7.

BlÁZOVICS, A., FEHÉR, E., ABDEl-RAHMAN, M., PRECHL, J., ÁGOSTON, M., FEHÉR, J. (1996): Free radicals in connection of bile and liver. Ces. A Slov. Gastroent., 50(3), 73-78.

BLOIS, M. S. (1958): Antioxidant determination by the use of a stable free radical. Nature, 4617, 1198-1200.

Bouchard, G., Chevalier, S., PereA, A., Barriault, C., Yousef, I. M. \& TuChweber, B. (1998): Role of glutathione in beneficial effect of dietary restriction on bile formation in young, mature, and old rats. J. Geront. Series A, Biol. Sci. Med. Sci., 53(5), B340-6.

CASellas, F., Mourelle, M., PAPO, M., GuARner, F., ANTOlin, M., ARMENGOl, J. R. \& MAlaGelaDA, J. R. (1996): Bile acid induced colonic irritation stimulates intracolonic nitric oxide release in humans. Gut, 38(5), 719-23.

EDER, I. M., Miquel, J. F., JÜngSt, D., PAumgartner, G., VON RitTer, C. (1996): Reactive oxygen metabolites promote cholesterol crystal formation in model bile: role of lipid peroxidation. Free Rad. Biol. Med., 20, 743-749.

EllmanN, G. L. (1959): Tissue sulfhydril group. Arch. Biochem. Biophys., 82, 70-76.

FEHÉR, E., BLÁZOVICS, A., HORVÁTH, É. M., KÉRY, Á., PETRI, G., FEHÉR, J. (1993): Effect of Sempervivum tectorum extract in the experimental hyperlipidemia and alcoholism. A histological study in the liver and jejunum. -in: Role of free radicals in biological systems. FEHÉR, J., BLÁZOVICS, Á., MATKOVICS, B., MÉZES, M. (Eds), Akadémiai Kiadó, Budapest, pp. 45-47.

HATANO, T., KAGAWA, H., YASUHARA, T. \& OKUDA, T. (1988): Two new flavonoids and other constituents in cichore root: their relative astringency and radical scavenging effects. Chem. pharm. Bull., 36, 2090-2097.

LING, S. C., WEAVER, L. T. (1997): The fate of fat in the infant's colon. QJM, 90, 553-5.

LOWRY, O. H., RosenBrough, N. J., FARR, A. L. \& RANDALl, B. J. (1951): Protein measurement with the Folin-phenol reagent. J. biol. Chem., 193, 265-275.

Martinez, J. D., Stratagoules, E. D., Larue, J. M., Powell, A. A., Gause, P. R., Craven, M. T., PAYNE, M. B., GERNER, E. W. \& EARNEST, D. L. (1998): Different bile acids exhibit distinct biological effects: the tumor promoter deoxycholic acid induces apoptosis and the chemoprotective agent ursodeoxycholic acid inhibits cell proliferation. Nutr. Canc., 31(2), 111-8.

OYAIZU, M. (1986): Studies on products of browning reaction prepared from glucosamine. Jpn. J. Nutr., 44, 307-15.

PEIFFER, L. P., PETERS, D. S. \& MCGARRITY, T. J. (1997): Differential effects of deoxycholic acid on proliferation of neoplastic and differentiated colonocytes in vitro. Dig. Dis. Sci., 42, 2234-2240.

POTTER, J. D., SLATTERY, M. L., BOSTICK, R. M. \& GAPSTUR, S. M. (1993): Colon cancer: A review of the epidemiology. Epidemiol. Rev., 15, 499-545.

Revised Guide for the Care and Use of Laboratory Animals (1996): NCR, Washington, DC.

SEDLAK, J. \& LINDSAY, R. H. (1968): Estimation of total, protein bound and non protein sulfhydril groups in tissues with Ellmann's reagent. Anal. Biochem., 25, 192-205.

SEYMOUR, I., SCHWARTZ, I., SHIRES, G. T., SPENCER, F. C. \& HuSSER, W. C. (1989): Principles of surgery. McGraw-Hill Inc., New York, p. 1270.

SHEKELS, L. L., LYFTOGT, C. T. \& HO, S. B. (1996): Bile acid-induced alteration of mucin production in differentiated human colon cancer cell lines. Int. J. Biochem. Cell. Biol., 28(2), 193-201.

SIPOS, P., GAMAL, E. M., BlÁZOVICS, A., METZGER, P., MikÓ, I. \& FurKA, I. (1997): Free radical reactions in the gallbladder. Acta Chir. Hung., 36, 329-31.

VelazQueZ, O. C., SETO, R. W., BAIN, A. M., FiSHER, J. \& ROMBEAU, J. L. (1997): Deoxycholate inhibits in vivo butyrate-mediated BrDU labeling of the colonic crypt. J. Surg. Res., 69(2), 344-8.

Xu, G., Salen, G., Tint, G. S., Hguyen, L. B., PArker, T. T., Chen, T. S., Roberts, J., KonG, X. \& GRENBLATT, D. (1998): Regulation of classic and alternative bile acid synthesis in hypercholesterolemic rabbits: effects of cholesterol feeding and bile acid depletion. J. Lipid Res., $39(8), 1608-15$ 